\title{
The Social Determinants of Cognitive Bias: The Effects of Low Capability on Decision Making in a Framing Experiment ${ }^{1}$
}

\section{Charles Plante ${ }^{2}$}

Ph.D. Candidate, Department of Community Health and Epidemiology, University of Saskatchewan

Phone: +1 306514 0890. Email: charles.plante@usask.ca

\section{Rim Lassoued}

Professional Research Associate, Department of Agricultural and Resource Economics, University of Saskatchewan

Ph:+1 306966 4027. Email: rim.lassoued@usask.ca

\section{Peter W.B. Phillips}

Distinguished Professor, Johnson-Shoyama Graduate School of Public Policy, University of Saskatchewan

Ph: +1 306966 4021. Email: peter.phillips@usask.ca

\footnotetext{
${ }^{1}$ Acknowledgements: The authors would like to thank Axel van den Berg, Steven Rytina, Shinobu Kitayama, and anonymous reviewers for their helpful comments and suggestions. The authors declare that they have no conflict of interest.

${ }^{2}$ Corresponding author.
} 


\title{
The Social Determinants of Cognitive Bias: The Effects of Low Capability on Decision Making in a Framing Experiment
}

\begin{abstract}
$\underline{\text { Abstract }}$
According to leading sociological thinking, the mind is shaped by wider society. In this study, we administer a modified version of Tversky and Kahneman's seminal framing experiment to a large and representative sample of Canadians. Our design allows us to explore which groups of people actually exhibit different cognitive biases. We find that the majority of people in our experiment do not exhibit loss aversion bias and that several people exhibit an opposite bias we call "turtling." Turtlers prefer smaller certain options when choices are framed as losses and larger uncertain options when they are framed as gains. People that suffer low capability, measured by a person's risk of experiencing low income based on their socio-demographic characteristics, are far more likely to turtle than others.
\end{abstract}

\section{Keywords}

Framing, cognitive bias, turtling, loss aversion, dual process theory, capability 


\section{Introduction}

Tversky and Kahnemen's now seminal framing experiment led them to articulate prospect theory $(1979 ; 1992)$ as an empirically grounded alternative to neoclassical theories of decision making (Barberis, 2012). In the years since, a burgeoning literature has emerged around framing effects in particular (A. Kühberger, 1998; I. P. Levin et al., 1998) and heuristics and cognitive biases more generally (Wilke et al., 2012). However, even though framing relates to understanding and language, and so practically begs for a sociological explanation, this research program has yet to materialize (Oishi et al., 2009; Zerubavel, 2009).

That social factors are generally still ignored in studies of the mind is made all the more surprising considering the growing supremacy of the dual process theory of mind (Evans, 2003). According to this view, people make most choices out of habit—termed "Type 1" processing. People can also overrule habitual decisions and develop new habits by reflecting on choices as they make them and being deliberate-termed invoking "Type 2" processing (Croskerry et al., 2013; Stanovich et al., 2008).

Social context plays a large role in which choices people are likely to make time and time again and which choices people make a conscious decision to alter. In applied fields, dual process theory has motivated new research on "debiasing" which explores how people can overcome and manipulate their Type 1 thinking (Bazerman et al., 2009; Croskerry, 2009b; Croskerry et al., 2013). Meanwhile, sociologist Stephen Vaisey (2009) has drawn on dual process theory to explain how culture can be both a source of motivation and justification for action. His conclusions echo Bourdieu's (1984) theory of class and habitus (see also, Lizardo, 2004).

The temptation to not seek sociological explanations for cognitive biases is likely bolstered by the fact that repeated framing studies have found similar results (A. Kühberger, 1998; I. P. Levin et al., 1998). However, nearly all of these studies have been administered to a very narrow and relatively privileged tranche of society: current and former students at elite universities (Kim et al., 2005) (see also, Henrich et al., 2010).

In order to explore the social determinants of cognitive bias, we administered a modified within-subjects version of Tversky and Kahneman's classic framing experiment (A. Kühberger, $1998)$ to a large sample $(N=486)$ of Canadians and collected information on their socio-demographic characteristics. Consistent with previously conducted within-subject experiments (Frisch, 1993; Irwin P. Levin et al., 2002; Mahoney et al., 2011; Stanovich et al., 1998), we find that the majority of respondents do not exhibit loss aversion and that a non-negligible number of respondents exhibit an opposite bias that could naively be seen as "loss seeking" but which we prefer to call "turtling.,"

Going beyond previous within-subject framing experiments, we explore how people's responses are mediated by their socio-demographic characteristics. We find that people who suffer "low capability" are far more likely to exhibit a heretofore untheorized response pattern we describe below and name "turtling." We operationalize low capability as an increased risk of suffering low income conditional on a person's observed socio-demographic characteristics, including their gender, age, minority status, aboriginal identity, disability status, country of

\footnotetext{
${ }^{1}$ There is some debate as to whether theses different ways of thinking should be referred to as "types" or "systems." Evans and Stanovich (2013) prefer "types" because it does not presuppose that the two processes are embedded in separate underlying neurological systems.

${ }^{2}$ Levin et al. (2002) find a similar result, but pay it little attention.
} 
origin, region of residence, family composition, employment status, level of education, and occupation.

Our findings shed important light on the nature of poverty and capability, their impact on decision making, and the origins of cognitive bias more generally. Crucially, our study is one of the first to demonstrate an empirical association between social context and the effects of cognitive bias on decision making. Our aim with this study is not to usurp previous research on cognitive biases but rather to add to it and motivate future investigation of their social determinants. ${ }^{3}$

\section{Motivation and key concepts}

\section{Tversky and Kahneman's framing experiment}

Three decades of experimental research in psychology and behavioural economics have shown that people on average do not make choices that align as expected with utility theory, the paradigm favoured by neoclassical economics (Wilke et al., 2012). In the late 1970s, Tversky and Kahneman proposed prospect theory (1979; see also 1992) as an empirically-grounded alternative that reflects the kinds of choices people actually make.

According to prospect theory people evaluate choices differently depending on how options are framed. ${ }^{4}$ Tversky and Kahneman (1981) famously demonstrated this using a framing experiment in which they presented two randomly selected groups of students with a hypothetical choice between pursuing certain and uncertain efforts to mitigate the spread of a deadly disease. For the first group, the options were presented in terms of gains as lives saved, and for the second in terms of losses as lives lost. Crucially, the mathematical expected value of all four options were the same. As such, any average difference in how each group decided would represent a deviation from classical utility theory and could only be attributed to differences between the frames that were presented to the students.

Tversky and Kahneman found that, on average, students in the group presented with options framed as losses were more likely to choose the uncertain outcome while students in the group presented with options framed as gains preferred the certain outcome. The fact that the students were willing to take on the associated costs of greater risk if alternatives of equal value were framed as losses was interpreted as evidence of a "loss aversion" bias.

Over the years, the experiment has been replicated many times with various modifications (A. Kühberger, 1998). As a whole, the loss aversion bias has been found to be widespread among those populations that have been presented with the problem.

\section{Social context and cognitive bias}

It is often assumed that people's cognitive biases and penchant for risk taking in the face of loss is the result of underlying and unchanging personal qualities, but sociological theories of the mind hint at alternative explanations (see also, Collins, 1989; Zerubavel, 2009). According to these theories, people's social perceptions and evaluations are shaped by their past experiences,

\footnotetext{
${ }^{3}$ For example, Mahoney et al. (2011) document how people with different "risk-styles" (Anton Kühberger, 1997) respond to framing experiments; our research suggests these styles may be acquired through processes of social learning.

${ }^{4}$ Barberis (2012) provides an accessible summary of prospect theory. In this paper, we focus on framing effects and loss aversion, but the complete theory describes other biases.
} 
which are in turn shaped by their social context. Recent advances in psychology that posit a dual process theory of the mind (Evans, 2003) lend increased credibility to this approach.

The word "bias" has a negative connotation, but recent work on cognitive biases has begun to distance itself from this interpretation (Wilke et al., 2012). Under the right material and social circumstances, most cognitive biases can be shown to be quite useful (for example,

Gigerenzer et al., 2011). This is because thinking rationally takes time and effort, so having the right biases can help us make good decisions when we do not have all the information or time needed to make the best decision.

Working with this idea, evolutionary psychologists have proposed evolutionary origins for some cognitive biases (for example, Haselton et al., 2009). For example, Haselton and Nettle (2015) list several biases, from auditory looming - a tendency to exaggerate movement when sounds are increasing in intensity - to xenophobia, which they argue humans are susceptible to, not because they improve the accuracy of our decisions but because they decrease the risk of making life threatening errors. The adaptation of these biases, however, operates on a timescale that leaves little room for social factors.

The dual process theory of the mind, however, allows for biases to be adapted within a lifetime. Although this theory acknowledges that there are innate cognitive biases, these biases can be overcome if people are concerted about the decisions they make, and new biases can be learned. Dual process theory posits that there are two distinct cognitive processes that underlie human reasoning: Type 1 and 2. Type 1 is fast and automatic and covers behaviours that are instinctive or habituated. Type 2 is slower but intentional and the type people ordinarily think of when they think of reasoning.

Crucially, via repeated deliberations people can "reprogram" their Type 1 reasoning processes (Stanovich et al., 2008). In applied settings, like medical diagnosis (Croskerry, 2009a; Croskerry et al., 2013) and business (Bazerman et al., 2009), this has motivated the study of "debiasing." By altering the conditions under which they make decisions, people can unlearn disadvantageous biases and habituate themselves to make better decisions. People can also train themselves to compensate for the most persistent biases.

Steven Vaisey (2009) postulates that the same mechanisms can operate implicitly. He draws on dual process theory to reconcile perceived contradictions between motivational and justificatory understandings of culture (DiMaggio, 1997). He observes that, "from a sociological perspective, we might expect that some unconscious tendencies would be socially patterned, differing systematically across "cognitive subcultures"' (1864), attributing the term "cognitive subcultures" to Zerubavel (2009).

Bourdieu's theory of habitus in many ways anticipates the new leading theory of mind (see also, Vaisey, 2009). Recast in terms of dual process theory, habitus is an assemblage of learned habitual biases that lead people from different classes to evaluate decisions differently. This dynamic is affirmed by research in psychology showing that powerful and non-powerful people manifest different biases (Fiske, 1993; Galinsky et al., 2006; Goodwin et al., 2000).

Returning to Tversky and Kahneman's influential framing experiment, in the next section we consider how social context might affect how people tend to approach the Tversky and Kahneman framing experiment. 


\section{Low capability and turtling}

Imagine two people, one for whom things usually work out well and another for whom this is not the case. Whereas classical utility theory posits that both should evaluate choices the same way - in terms of their immediate returns - Amartya Sen $(1985,2000)$ argues that outcomes should be evaluated not just in terms of their immediate returns but also in terms of the additional opportunities they can lead to. He calls these opportunities "capabilities."

Sen (2000) introduces his concept of capability in order to overcome economic theories of poverty and development that place too much emphasis on the resources people command in the present. In rich countries, this manifests as a preoccupation with personal income at the expense of other important determinants of well-being, like economic and political rights and the capacity to participate freely and meaningfully in society without discrimination.

Whether things tend to work out for the best for people is only partially determined by their immediate command of resources. It is also determined by their environmental and social contexts which dictate what they can and cannot do with them. "Low capability," is a condition in which an absence of opportunities reduces the scope of action available to a person thus making it less probable that they will be able to ensure things work out for the best for themselves.

Over the long term, two people with the same resources but different capability can reasonably expect different results. Based on their past experiences, the low capability person is unlikely to respond to Tversky and Kahneman's framing experiment in the same way as someone who possesses high capability.

The person for whom things usually work out is likely to undervalue large losses and gains. ${ }^{5}$ This is because a) they can expect to recover from large losses and b) large gains will be of lesser value to them because they can reasonably expect to achieve them eventually. This person is likely to exhibit the choice pattern described by Tversky and Kahneman as loss aversion.

In contrast, the low capability person will overvalue large losses and gains. For this person, a less likely but larger loss is potentially devastating in ways that a smaller but certain loss is less likely to be. ${ }^{6}$ Based on past experience, they cannot reasonably expect to recover from the largest losses. Similarly, if most gains for this person tend to eventually be lost over time, gains need to be particularly large to be worthwhile.

When confronted with Tversky and Kahneman's framing experiment, the low capability person may be more likely to exhibit a choice pattern we call "turtling," wherein they prefer a certain lesser gain when a choice is framed as losses and a less certain larger gain when the same choice is framed as gains. We call this choice pattern turtling because of the way that a turtle will withdraw into its shell when it is confronted with danger and hope that the threat moves on. At the same time, having few natural mechanisms of defence, it has to take great risks in order to survive.

In fact, in advanced industrialized economies like Canada, the vast majority of people can look forward to recovery from even large losses (for example, loss of job due to redundancy). In these countries, there are a myriad of market opportunities and government programs available to

\footnotetext{
${ }^{5}$ Summarizing Tversky and Kahneman work, Barberis (2012) calls this "diminishing sensitivity" (4).

${ }^{6}$ This overvaluing could be the result of either overestimating the value of the loss or overestimating its probability. These are, for all intent and purposes, the same (Prelec, 1998, p. 507).
} 
put people back on their feet (for example, unemployment insurance), which one would expect to introduce systemic upward pressure on people's well-being over time.

That having been said, not everyone benefits from the same life chances, and some people's chances are poor. Over the course of a lifetime, these individuals are likely to develop a "turtling" bias.

Surprisingly, even though Tversky and Kahneman's framing experiment has been reproduced dozens of times, study participants have nearly always been students at elite universities (A. Kühberger, 1998; I. P. Levin et al., 1998). Even in rare exceptions, when non-students have been surveyed, respondents have been no less WEIRD (for example, Loke et al., 1992; Roszkowski et al., 1990) - that is, Western, Educated, Industrialized, Rich, and residing in Democratic societies (Henrich et al., 2010).

In contrast to previous implementations of Tversky and Kahneman's experiment, we administered ours to a large and representative sample of Canadians and also collected information on respondents' socio-demographic characteristics. We use this to test the following hypothesis:

H1: People that have low capability are more likely to switch from being risk seeking if choices are framed as gains to being risk averse if choices are framed as losses-that is, they are more likely to turtle.

\section{Methodology}

\section{Data collection}

In 2015, we conducted an online ${ }^{8}$ self-administered questionnaire to a random sample of Canadians recruited through Probit, a national internet-based research company. This provided us with a nationally representative sample with respect to demographics, far more diverse than those ordinarily used in framing experiments and, with an $N$ of 486 , far larger. ${ }^{9}$

Before starting the survey, respondents were presented with a standard consent form describing the study and were assured that there were no known risks associated with their participation, that their responses would be kept anonymous, and that their participation was voluntary. In order to encourage participation, respondents were also compensated with a flat payment of $C \$ 5$ upon completion of the survey. A total of 1,395 individuals were invited to participate in the survey and 486 surveys completed it, representing a response rate of $35 \%$.

The research plan was reviewed and approved by the University of [anonymous] ethics board on February 25, 2014.

\footnotetext{
${ }^{7}$ In his meta-analysis of the literature on framing effects, Kühberger (1998) concludes that student and non-student groups "do not differ in their receptivity to the framing effect" (36). However, Kühberger's conclusion likely reflects the limited nature of the non-student samples he had to draw on.

${ }^{8}$ The questionnaire was administered by means of a web-based survey panel hosted by Qualtrics. The survey noted that responses would be collected by Qualtrics, which is subject to the US Patriot Act.

${ }^{9}$ For example, Levin et al. (2002) only sample 102 students in their similar within-subject experiment.
} 


\section{Our modified framing experiment}

Our modified version of Kahneman and Tversky's experiment differed in two important ways: first, we presented respondents with a problem framed as gains and losses related to Canadian biotechnological innovation, and thus altered its stakes; second, we administered both questions - one framed as gains and the other as losses - to each respondent.

\section{Different stakes}

In their original framing experiment, Kahneman and Tversky (1981) asked respondents to imagine they are making a decision in which people's lives are at stake. Alternatives are framed as gains by casting them in terms of the number of people that will survive a disease outbreak and as losses in terms of number of people that will die. Other researchers have replicated this experiment using different decisions whose consequences are less extreme. While the share of people that choose the uncertain outcome when the choice is framed as a loss generally tends to be greater, framing effects tend to be more muted when stakes are lower (Druckman, 2001).

In this paper, we examine the role that framing plays in decision making about the adoption of biotechnological innovation in Canada. We asked a heterogeneous sample of Canadians to choose among certain and uncertain technological alternatives relating to crop yields. These were framed as gains and losses by casting them in terms of crops saved and lost. For example, the positively framed choice was posed to respondents as follows:

Imagine that your country is preparing for the onset of severe environmental conditions, which are expected to destroy 51,750 producers' crops. Two alternative technologies developed as plants with novel traits (PNTs) have been proposed. Assume that the scientific estimates of the consequences of the technologies are as follows: If Technology $A$ is adopted, 17,250 producers' crops will be saved. If Technology B is adopted, there is $1 / 3$ probability that 51,750 producers' crops will be saved, and 2/3 probability that no producers' crops will be saved. Which of the two technologies would you favour?

- Technology $A$

- Technology $B$

Note that a definition of a PNT was provided at the start of the survey to ensure that participants understood the biotechnology of interest.

The consequences of the technologies were the same whether they were presented to respondents in terms of crops saved or lost (see Table 1). For the choice framed as gains, the sure option consisted of a gain of 17,250 crops saved and the risky option of a 1/3 probability that all 51,750 crops saved. Conversely, for the choice framed as losses, respondents were presented with a choice between allowing 34,500 crops to be lost or pursuing a risky alternative with a $2 / 3$ probability that all would be lost.

In their original framing experiment, Kahneman and Tversky observe that when the choice is framed as gains, people are 2.6 times more likely to prefer the certain option; however, when the choice is framed as losses, they are 3.5 times more likely to prefer the uncertain option. In our version of the experiment, we observed a more muted framing effect: people were 4.3 times more likely to prefer the certain option when it was framed as gains. When it was framed as losses, they were still more likely to prefer the certain option though only by a factor of 2 . 
The muted framing effects we observe could be the result of the lower stakes of the gambles we pose but could also reflect the far more heterogeneous composition of our sample.

Finally, it should be noted that the link that we draw between low capability and choices below is not likely biased by respondent's familiarity with farming and biotechnology. Farmers represent a relatively minuscule and shrinking segment of the Canadian population, which also tends to be quite affluent and so high capability (Statistics Canada, 2017).

\section{[TABLE 1 HERE]}

\section{A within-subject design}

We used a within-subject design (A. Kühberger, 1998) in our survey in order to explore a research question unrelated to this paper: whether the perceived source of a biotechnological innovation mediated the effect of framing on decision making. Fortuitously, this provided us with a way to isolate individuals that actually changed their choices conditional on framing and explore the impact of external factors on these decisions.

There are precedents for this kind of design. For example, in their within-subject experiment, Levin et al. (2002) found that only just under $20 \%$ of student respondents exhibited the kinds of switching behaviour predicted by Kahneman and Tversky and an even smaller share switched in the opposite direction (Frisch (1993) and Stanovich and West (1998) report similar findings). When different frames are posed to different groups as in the original experiment, the net effect of these unequal switching patterns leads to the loss aversion interpretation. Mahoney et al. (2011) take the use of the within-subject design one step further and explore how people's risk preferences affect their responses.

Our survey was administered in four sections. In the first and third sections, positively and negatively framed questions were posed in a random order to respondents. Between these two sections, participants were asked several math skill questions to deter memorization of the first question. Section 4 asked respondents several questions about their socio-demographic characteristics.

Additionally, we randomized the order in which positively or negatively framed choices were presented to respondents. This allows us to control for whether this ordering had an impact on people's switching behaviour (Perreault, 1975). ${ }^{10}$

\section{Operationalizing low capability}

Low capability relates not to a person's present command of resources but to the amount of resources and opportunities people can reasonably expect to command over the long run should they so choose (Sen, 1985, 2000). In this study, we estimate the effect that contextual factors, operationalized as the combination of a person's various socio-demographic characteristics, have on their risk of suffering low income.

Capability, which relates to the opportunities people possess, is a notoriously difficult concept to measure (Anand, Santos, and Smith 2007). Nonetheless, income and capability tend to be correlated in developed countries like Canada (Duclos 2002; Kuklys 2005). A vast

\footnotetext{
${ }^{10}$ Note that this design also exactly replicates the original between experiment in its first stage. Randomization created two groups, one of which receives the choice framed as gains first and the other framed as losses.
} 
literature also confirms that various socio-demographic groups face different risks of income-based poverty (Sharma 2012).

In recent years, a handful of poverty researchers have proposed using low income to operationalize low capability (Brady, 2003; Kuklys, 2005). However, low income alone will not capture the full extent of low capability. This is because oftentimes two individuals with the same level of income will not have access to the same opportunities. Broadly speaking, there can be people that have low income but high capability and vice versa.

That having been said, it is also recognized that people with low capability, all things being equal, are far more likely to suffer low income. It stands to reason, then, that rather than measure low capability using low income, we might instead measure low capability as a heightened risk of low income. We submit that the risk of low income conditional on the characteristics of persons observed in this study provides a potentially useful "indirect" (Sen, 2000, p. 81) measure of low capability.

We operationalize low income as a respondent reporting living in a household whose total is less than $\$ 25,000$ a year. This threshold is comparable to income-based poverty thresholds widely used in Canada (Statistics Canada 2016).

\section{Measuring the effect of capability on turtling}

In order to measure the effect of capability on turtling in our data, we fit a system of two equations: one which describes the probability that a person turtles and another which describes the probability that they suffer low income conditional on their observed socio-demographic characteristics. Estimating this model is equivalent to estimating a probit regression with instrumental variables and is fitted using maximum likelihood estimation in Stata using the command ivprobit.

With $t^{*}{ }_{i}$ as the latent probability that person $i$ will turtle and $c^{*}{ }_{i}$ as the probability that they will suffer low income, the system of two equations we estimate is:

$$
\begin{aligned}
& t_{i}^{*}=\mu+c_{i}^{*} \beta+\epsilon_{i} \\
& c_{i}^{*}=\mathbf{Z}_{\mathbf{i}} \gamma+v_{i}
\end{aligned}
$$

where $Z_{i}$ is a matrix of observed person-specific socio-demographic characteristics; $\mu, \beta$, and $\gamma$ are model parameters that we estimate; $\epsilon_{i}$ is an error term with a mean of zero and a variance of 1 ; and $v_{i}$ is an error term with a mean of zero and a variance of $\sigma^{2}$. $^{11}$

We assess our hypotheses that low capability individuals are more likely to turtle when they are presented with our framing experiment by estimating Equation 1. Our hypothesis posits that $\beta$ will be positive and statistically significant. Our null hypothesis is that capability has either no effect or a negative effect on the probability, that is: $H_{0}: \beta \leq 0$.

Equation 2 fits a person's probability of suffering low capability, operationalized as their risk of experiencing low income conditional on their socio-demographic characteristics. We

\footnotetext{
${ }^{11}$ Heckman and Robb (1985) observe that there is no need to use a nonlinear specification for the second equation when it is not the focus. This is because even though the linear specification will bias specific estimates in the equation, it will not affect the overall estimation of the probability of the outcome. Stata's ivprobit automatically estimates the first equation as a probit model and the second as a linear model.
} 
estimate the system of Equation 1 and 2 five times, each time including different socio-demographic variables in $Z_{i}$. Table 2 summarizes the variables that we work within this study, their codings, and how we anticipate their levels to be associated with capability.

\section{[TABLE 2 HERE]}

In Model 1, we regress turtling on low income. Model 2 instruments low income using all the socio-demographic variables listed in Table 2. Model 3 drops employment status and work setting which are arguably transitory. Model 4 drops characteristics that are acquired: highest level of education and occupation. Finally, Model 5 regresses turtling on only education and occupation.

In every model, we also control for the order in which respondents received the choice framed as gains or losses (using having received the choice framed as losses first as the reference category). This allows us to account for any potential order-effect bias (Perreault, 1975).

\section{$\underline{\text { Results }}$}

\section{Sample characteristics}

In order to verify the representativeness of our online sample, we compared it to Statistics Canada's 2015 Canadian Community Health Survey Public Use Microdata File (CCHS-PUMF), which collected information on many of the same variables. ${ }^{12}$

Our sample is basically identical to the Canadian population in terms of gender, familial composition, employment status, occupation, and region of residence. It is also broadly similar in terms of shares reporting various indicators of vulnerability, including disability, being born outside Canada, and low income status. However, our sample is slightly younger and better educated than the wider Canadian population, and visible minorities are underrepresented by half. These deviations are to be expected in an internet-based survey.

Table 3 summarizes the distribution of switching patterns in our sample. As in Levin et al. (2002) the majority of our sample did not alter their penchant for risk in the face of gain and loss framing and only about $20 \%$ exhibit the switching pattern made famous by Kahneman Tversky. However, in our sample, about $6 \%$ of respondents did exhibit the converse switching pattern that is the focus of this paper. This is about three times greater than the share reported by Levin at al. and likely reflects the greater diversity of our sample.

\section{[TABLE 3 HERE]}

Table A1 in the appendix summarizes the distribution of turtling among the different socio-demographic characteristics we use to estimate the probability of suffering low capability. ${ }^{13}$ Broadly speaking, groups that we would expect to suffer lower capability are more likely to turtle. However, because our sample size is relatively small, most of these differences are not individually statistically significant.

\footnotetext{
12 These comparisons are available from the authors upon request.

13 Tables that report sample sizes and exact estimates and confidence intervals for each kind of switching and every kind of demographic distinction can be provided by the authors upon request.
} 


\section{Fitted low capability effects}

Table 4 summarizes the key results of the five model specifications we fit (we provide a complete table of estimates for Models 2 through 5 in Table A2 in the appendix-Table 4 contains all the estimates for Model 1). In summary, all five models produce estimates of the effect of low capability on the probability of turtling that are positive, affirming our hypothesis; however, these vary in their intensity and not all are statistically significant.

Model 1 estimates the predicted probability of turtling conditional solely on low income. Not surprisingly, this is not found to be statistically significant, although the effect is estimated to be positive and small. This likely reflects the fact that low income alone is not a good predictor of a person's reasonably expected fortunes.

On the other hand, regressing the predicted probability of turtling on low capability measured by the risk of low income produces effect sizes that are greater and statistically significant at the $90 \%$ level or greater in three of the four remaining models. Only in Model 4 , which measures the risk of low income conditional on only ascribed characteristics, is the effect not statistically significant. This result likely reflects the outsized importance of acquired characteristics in determining status and mobility in Canadian society (Blanden, 2013).

The results in Models 2, 3, and 5 indicate large and statistically significant effects of low capability on the predicted probability of turtling. Although the effect is greatest in the most pared down model (Model 5), this model has a much larger Akaike Information Criterion (AIC) score than the other two, suggesting that the first two are a better fit. Model 3, which excludes transitory attributes, strikes an effective compromise between model fit and parsimony.

Estimated effect sizes are considerable. In our preferred model, Model 3, a one unit increase in a person's risk of low income is estimated to increase their predicted probability of turtling by 2.0 standard deviations over and above a constant of -1.7 along the standard normal cumulative density function.

In order to make these numbers easier to understand, it helps to convert them back into ordinary probabilities. They indicate that a person with high capability, measured as no risk of low income, has about a 4\% chance of turtling. Meanwhile, an individual with low capability, measured by a definite risk of low income, has about a $62 \%$ chance of turtling. Of course, it should be noted that in practice, $c^{*}{ }_{i}$ does not take on values 0 or 1 . In fact, its highest observed value in our sample is just under 0.5 , corresponding to a probability of turtling of about $24 \%$.

Excluding ascribed characteristics like age or minority status as we do in Model 5 dramatically inflates the effect of low capability on the probability of turtling. This suggests that even though their impact is minor when only they are accounted for in Model 4, they still have an important role to play. The reduction of the effect of the risk of low income on turtling between Models 5 and 3 implies that there are aspects of the relationship between ascribed characteristics and low income that operate independently of their impact on turtling.

In 5 models, the effect of the order in which respondents were presented with the choice framed as gains or losses is small and had no statistically significant effect on whether respondents chose to turtle. We also estimated all our models without controlling for this ordering and estimates of $\beta$ and $\mu$ were statistically indistinguishable.

\footnotetext{
14 Though Model 2 fares slightly better than Model 3 with respect to the AIC, it fails the Wald test of exogeneity (reported in the complete table of estimates provided in the appendix).
} 


\section{$\underline{\text { Discussion }}$}

\section{The social determinants of cognitive bias}

Since the path-breaking work of Kahneman and Tversky (1981), researchers have extensively documented the ways in which a relatively homogenous group of people make decisions and how their decisions deviate from the so-called "rational" assessments of classical utility theory. Our study is among the first to administer a gain-loss framing experiment to a large, diverse, nationally representative sample.

Our results suggest that even within relatively WEIRD populations there is room for variation in responses to classic behavioural experiments when factors like education and wealth are allowed to vary. We find that low capability, measured as a person's risk of low income conditional on their socio-demographic characteristics, can be a useful indicator of whether they are likely to turtle or not.

That having been said, rather than interpret our results as contributing to a case that could be made against Kahneman and Tversky's theories of cognitive bias, we prefer to interpret them as an affirmation of this school of thought. In short, we find that the switching pattern they describe is indeed the most prevalent pattern of switching found in the Canadian population (when non-switchers are excluded). Our results also replicate the general findings of previous studies that implement a within-subject design.

However, our results begin to articulate an empirical and explanatory basis for these biases. In recent years, a handful of studies have considered how framing effects operate differently conditional on socio-demographic attributes like gender (Fagley et al., 2016) and age (Kim et al., 2005). Mahoney et al. (2011) consider how different personality types are likely to lead people to assess risk and certainty under various framing conditions differently. Our study provides a plausible and empirically-backed explanation for some of these differences, as well as for differences among groups that have yet to be studied.

In this paper, we explore the relationship between socio-demographic attributes and people's propensity to turtle in a framing experiment. This is only one of the four different switching patterns that we observed. In fact, our preliminary results suggest some of the other three patterns are also associated. For example, no low income individuals were risk seeking in the face of both gain and loss framing.

\section{Reconsidering the irrationality of the disadvantaged}

Our findings inform a growing body of research that explores how the disadvantaged make decisions. Within this field, there are roughly two bodies of literature (Duflo, 2006): one which studies how poverty stresses the poor and impedes their ability to process decisions (Mani et al., 2013) and another that studies how the material realities of the poor lead them to make decisions that are rational to them but are likely to seem irrational to others (Haushofer et al., 2014). Our research informs both.

Cognitive biases are generally construed as irrational (Lopes, 2016); however, in this paper we argue that people's differential sensitivity to risk in the face of different framing may arise in response to social circumstances. To an outsider, turtling may appear to be loss seeking,

\footnotetext{
${ }^{15}$ Tversky and Kahneman's framing experiment has not been administered to this kind of sample, but other related tests of cognitive bias have. In particular, tests designed to measure optimism and pessimism bias (Chapin, 2001; Weinstein, 1987).
} 
but to a disadvantaged person, this could be a learned disposition and the only reasonable response to a lifetime littered with choices that pose potentially devastating consequences (see also "precautionary savings" (Lusardi, 1998)).

That being said, as strategies like turtling become increasingly ingrained, even to the point of becoming cognitive biases, the risk that they will be applied in counterproductive and ultimately irrational ways is increased. Regardless of the merits of turtling being applied to the matter of biotechnological innovations in Canadian agriculture, on average, low capability respondents appear to have carried their learned habit of turtling into the experiment.

Though beyond the scope of this study, people who suffer low capability are not likely the only ones whose past experiences can lead them to develop potentially counterproductive biases. For example, individuals for whom things always tend to work out could develop potentially dangerous levels of diminished sensitivity to risk. This concern is a familiar one in the literature on optimism and pessimism biases (Sharot, 2011).

Whether we are concerned by framing biases among the poor or non-poor, a growing body of literature suggests that these can be avoided; people only need to be encouraged to reflect on their decisions (Frisch, 1993; McElroy et al., 2003). When their System 2 analytic reasoning abilities are engaged, they are more likely to correctly assess prospects and make decisions that fall in line with classic utility.

\section{A novel method for measuring capability}

Capability is a notoriously difficult concept to measure, even though theory predicts that it should be associated with a variety of outcomes. In contrast to related measures of well-being, like low income, capability describes people's real opportunities more directly and is thus more likely to be associated with how they interpret the world around them and make decisions.

In this study, we argue that a person's risk of low income is a plausible indicator of low capability and find it to be associated with the propensity to turtle in the face of decisions framed as losses or gains. Interestingly, we also find that low income is not directly associated with our outcome of interest and that only risk of low income is.

These results are consistent with the finding that it is not low income that shapes people's risk aversion, another cognitive disposition, but rather their command of assets and associated capacity to cope with risk (Mosley et al., 2005). Poverty is a set of circumstances that shapes how people navigate the world. Just because a person comes into higher income one day does not mean that they are then as equally well-off as someone that has always had that level of income.

Examining a person's risk of misfortune potentially provides a more direct method for capturing the impacts of poverty in people's lives than simply measuring their present well-being. This approach would appear to be especially apt when the goal is to capture the impact of low income on cognition. However, as a new measure, it will benefit from further validation studies.

\section{Conclusion}

We administered a within-subject framing experiment to a demographically representative sample of 486 Canadians. Respondents were presented with two randomly ordered sets of choices between two biotechnological innovations that would either save crops or reduce losses in response to a hypothetical agricultural disaster. In each set, one option was certain and the other uncertain, but both were of equal value. 
Even though the vast majority of respondents did not switch their preference for the certain or uncertain option based on whether the choices were framed in terms of gains or losses, the majority of those that did, preferred uncertainty in losses, thus confirming the established framing effect initially described by Kahneman and Tversky (1981). Nonetheless, about $6 \%$ of respondents preferred the certain option in losses and the uncertain one in gains.

In this paper, we theorize and model the socio-demographic precedents of this group of non-traditional switchers. We draw on the work of development economist Amartya Sen (1985, 2000) to argue that this pattern of choices, which we call "turtling," would be consistent for someone that suffered low capability and thus a disproportionate risk of short term losses that have long term consequences.

We find robust statistical evidence that low capability, measured by a person's risk of experiencing low income conditional on various socio-demographic characteristics, is strongly positively associated with their likelihood of turtling. Furthermore, we find that the order in which the choices were presented to respondents does not mediate this relationship - that is, our within-subject design is not undermined by order-effect bias.

Our results have important implications for how we understand poverty, decision making, and cognitive biases. Narrowly, we interpret our results to suggest that the effect of framing on the decisions of the poor is likely a learned response. On the other hand, as this response becomes increasingly habitual, it can become a bias that will prejudice their choices in unexpected and potentially harmful ways.

In a world where governments are using prospect theory to design the choice architecture facing citizens and where nudges are becoming more commonplace (Thaler and Sunstein 2008), it is important that policy makers not fall into the trap of assuming all individuals will respond in the way that prospect theory hypothesizes.

Broadly, our results not only confirm Kahneman and Tversky's claim that people's decisions are affected by bias but also bolster it by providing an empirically-grounded reason for why these biases exist in the first place. We hope that these results motivate further exploration of the social determinants of cognitive biases.

\section{References}

Barberis, N. C. (2012). Thirty Years of Prospect Theory in Economics: A Review and Assessment (Working Paper 18621). National Bureau of Economic Research.

Bazerman, M. H., \& Moore, D. A. (2009). Judgment in Managerial Decision Making. Hoboken, NJ: John Wiley \& Sons.

Blanden, J. (2013). Cross-country Rankings in Intergenerational Mobility: A Comparison of Approaches from Economics and Sociology. Journal of Economic Surveys, 27(1), 38-73.

Bourdieu, P. (1984). Distinction: A Social Critique of the Judgement of Taste. Cambridge, Mass: Harvard University Press.

Brady, D. (2003). Rethinking the sociological measurement of poverty. Social Forces, 81, $715-751$.

Chapin, J. (2001). Self-protective Pessimism: Optimistic Bias in Reverse. North American Journal of Psychology, 3(2), 253-261.

Collins, R. (1989). Toward A Neo-Meadian Sociology of Mind. Symbolic Interaction, 12(1), $1-32$.

Croskerry, P. (2009a). Context is everything or how could I have been that stupid? Healthcare 
Quarterly, 12 Spec No Patient, e171-e176.

Croskerry, P. (2009b). Clinical cognition and diagnostic error: applications of a dual process model of reasoning. Advances in Health Sciences Education: Theory and Practice, 14 Suppl $1,27-35$.

Croskerry, P., Singhal, G., \& Mamede, S. (2013). Cognitive debiasing 1: Origins of bias and theory of debiasing. BMJ Quality \& Safety, 22 Suppl 2, ii58-ii64.

DiMaggio, P. (1997). Culture and Cognition. Annual Review of Sociology, 23(1), 263-287.

Druckman, J. N. (2001). Evaluating framing effects. Journal Of Economic Psychology, 22(1), 91-101.

Duflo, E. (2006). Poor but Rational? In Understanding Poverty. New York: Oxford University Press.

Evans, J. S. B. T. (2003). In two minds: dual-process accounts of reasoning. Trends in Cognitive Sciences, 7(10), 454-459.

Evans, J. S. B. T., \& Stanovich, K. E. (2013). Dual-Process Theories of Higher Cognition: Advancing the Debate. Perspectives on Psychological Science: A Journal of the Association for Psychological Science, 8(3), 223-241.

Fagley, N. S., \& Miller, P. M. (2016). The Effect of Framing on Choice. Personality \& Social Psychology Bulletin.

Fiske, S. T. (1993). Controlling other people. The impact of power on stereotyping. The American Psychologist, 48(6), 621-628.

Frisch, D. (1993). Reasons for Framing Effects. Organizational Behavior and Human Decision Processes, 54(3), 399-429.

Galinsky, A. D., Magee, J. C., Inesi, M. E., \& Gruenfeld, D. H. (2006). Power and perspectives not taken. Psychological Science, 17(12), 1068-1074.

Gigerenzer, G., \& Gaissmaier, W. (2011). Heuristic decision making. Annual Review of Psychology, 62, 451-482.

Goodwin, S. A., Gubin, A., Fiske, S. T., \& Yzerbyt, V. Y. (2000). Power Can Bias Impression Processes: Stereotyping Subordinates by Default and by Design. Group Processes \& Intergroup Relations: GPIR, 3(3), 227-256.

Haselton, M. G., Bryant, G. A., Wilke, A., Frederick, D. A., Galperin, A., Frankenhuis, W. E., \& Moore, T. (2009). Adaptive Rationality: An Evolutionary Perspective on Cognitive Bias. Social Cognition, 27(5), 733-763.

Haselton, M. G., Nettle, D., \& Murray, D. R. (2015). The Evolution of Cognitive Bias. In The Handbook of Evolutionary Psychology. John Wiley \& Sons, Inc.

Haushofer, J., \& Fehr, E. (2014). On the psychology of poverty. Science, 344(6186), 862-867.

Heckman, J. J., \& Robb, R., Jr. (1985). Alternative methods for evaluating the impact of interventions : An overview. Journal of Econometrics, 30(1-2), 239-267.

Henrich, J., Heine, S. J., \& Norenzayan, A. (2010). The weirdest people in the world? The Behavioral and Brain Sciences, 33(2-3), 61-83; discussion 83-135.

Kahneman, D., \& Tversky, A. (1979). Prospect Theory: An Analysis of Decision under Risk. Econometrica: Journal of the Econometric Society, 47(2), 263-291.

Kim, S., Goldstein, D., Hasher, L., \& Zacks, R. T. (2005). Framing effects in younger and older adults. The Journals of Gerontology. Series B, Psychological Sciences and Social Sciences, 60(4), P215-P218.

Kühberger, A. (1997). Theoretical conceptions of framing effects in risky decisions. In R. 
Ranyard, W. Ray Crozier, \& O. Svenson (Eds.), Decision Making: Cognitive Models and Explanations (pp. 128-144). Routledge London.

Kühberger, A. (1998). The Influence of Framing on Risky Decisions: A Meta-analysis.

Organizational Behavior and Human Decision Processes, 75(1), 23-55.

Kuklys, W. (2005). Amartya Sen's Capability Approach: Theoretical Insights and Empirical Applications. Berlin: Springer.

Levin, I. P., Gaeth, G. J., Schreiber, J., \& Lauriola, M. (2002). A New Look at Framing Effects: Distribution of Effect Sizes, Individual Differences, and Independence of Types of Effects. Organizational Behavior and Human Decision Processes, 88(1), 411-429.

Levin, I. P., Schneider, S. L., \& Gaeth, G. J. (1998). All Frames Are Not Created Equal: A Typology and Critical Analysis of Framing Effects. Organizational Behavior and Human Decision Processes, 76(2), 149-188.

Lizardo, O. (2004). The Cognitive Origins of Bourdieu's Habitus. Journal for the Theory of Social Behaviour, 34(4), 375-401.

Loke, W. H., \& Tan, K. F. (1992). Effects of framing and missing information in expert and novice judgment. Bulletin of the Psychonomic Society, 30(3), 187-190.

Lopes, L. L. (2016). The Rhetoric of Irrationality. Theory \& Psychology.

Lusardi, A. (1998). On the Importance of the Precautionary Saving Motive. The American Economic Review, 88(2), 449-453.

Mahoney, K. T., Buboltz, W., Levin, I. P., Doverspike, D., \& Svyantek, D. J. (2011). Individual differences in a within-subjects risky-choice framing study. Personality and Individual Differences, 51(3), 248-257.

Mani, A., Mullainathan, S., Shafir, E., \& Zhao, J. (2013). Poverty impedes cognitive function. Science, 341(6149), 976-980.

McElroy, T., \& Seta, J. J. (2003). Framing effects: An analytic-holistic perspective. Journal of Experimental Social Psychology, 39(6), 610-617.

Mosley, P., \& Verschoor, A. (2005). Risk Attitudes and the "Vicious Circle of Poverty." The European Journal of Development Research, 17(1), 59-88.

Oishi, S., Kesebir, S., \& Snyder, B. H. (2009). Sociology: a lost connection in social psychology. Personality and Social Psychology Review: An Official Journal of the Society for Personality and Social Psychology, Inc, 13(4), 334-353.

Perreault, W. D. (1975). Controlling Order-Effect Bias. Public Opinion Quarterly, 39(4), 544-551.

Prelec, D. (1998). The Probability Weighting Function. Econometrica: Journal of the Econometric Society, 66(3), 497-527.

Roszkowski, M. J., \& Snelbecker, G. E. (1990). Effects of "Framing” on measures of risk tolerance: Financial planners are not immune. The Journal of Behavioral Economics, 19(3), 237-246.

Sen, A. (1985). Commodities and Capabilities. Amsterdam: North-Holland.

Sen, A. (2000). Development as Freedom (Reprint). Anchor.

Sharot, T. (2011). The optimism bias. Current Biology: CB, 21(23), R941-R945.

Stanovich, K. E., \& West, R. F. (1998). Individual Differences in Framing and Conjunction Effects. Thinking \& Reasoning, 4(4), 289-317.

Stanovich, K. E., \& West, R. F. (2008). On the relative independence of thinking biases and cognitive ability. Journal of Personality and Social Psychology, 94(4), 672-695. 
Statistics Canada. (2017). A portrait of a 21st century agricultural operation. Statistics Canada. Tversky, A., \& Kahneman, D. (1981). The framing of decisions and the psychology of choice. Science, 211(4481), 453-458.

Tversky, A., \& Kahneman, D. (1992). Advances in prospect theory: Cumulative representation of uncertainty. Journal of Risk and Uncertainty, 5(4), 297-323.

Vaisey, S. (2009). Motivation and Justification: A Dual-Process Model of Culture in Action. The American Journal of Sociology, 114(6), 1675-1715.

Weinstein, N. D. (1987). Unrealistic optimism about susceptibility to health problems: conclusions from a community-wide sample. Journal of Behavioral Medicine, 10(5), 481-500.

Wilke, A., \& Mata, R. (2012). Cognitive Bias. In V. S. Ramachandran (Ed.), The Encyclopedia of Human Behavior (Vol. 1, pp. 531-535). Academic Press.

Zerubavel, E. (2009). Social Mindscapes: An Invitation to Cognitive Sociology. Harvard University Press. 
Table 1. Structure of the modified Asian disease problem

\begin{tabular}{cccc}
\hline Frame & Choice option & Consequence & Expected value (equivalent) \\
\hline \multirow{2}{*}{ Positive } & Tech. A & 17,250 saved & 17,250 saved $(34,500)$ lost \\
& Tech. B & $(1 / 3) 51,750$ saved & 17,250 saved $(34,500)$ lost \\
\multirow{2}{*}{ Negative } & Tech. A & 34,500 lost & 34,500 lost $(17,250$ saved) \\
& Tech. B & $(2 / 3) 51,750$ lost & 34,500 lost $(17,250$ saved) \\
\hline
\end{tabular}


Table 2. Social distinctions and their dominance in the Canadian sample $(\mathrm{N}=486)$

\begin{tabular}{|c|c|c|c|}
\hline Distinction & More capability & Less capability & Unclear \\
\hline Gender & Male & Female & \\
\hline Age group & Baby Boomer & Millennial & Gen X \\
\hline $\begin{array}{l}\text { Highest level of } \\
\text { education }\end{array}$ & $\begin{array}{l}\text { University degree or } \\
\text { greater }\end{array}$ & High School or less & Technical degree \\
\hline Employment status & Employed & Not employed & Retired \\
\hline Work setting & & & All categories \\
\hline Occupation & $\begin{array}{l}\text { Management, Business } \\
\text { \& finance, Natural } \\
\text { sciences }\end{array}$ & $\begin{array}{l}\text { Sales \& services, Trades } \\
\& \text { manufacturing }\end{array}$ & $\begin{array}{l}\text { Health, Other } \\
\text { professional }\end{array}$ \\
\hline Region of Canada & Central & Eastern, North & West \\
\hline Family composition & Couple no kids & Single with kids & Single, Couple with kids \\
\hline Minority status & Non-minority & Minority & \\
\hline Aboriginal identity & Non-aboriginal & Aboriginal & \\
\hline Disability & No disability & Disability & \\
\hline Born abroad & Non-immigrant & Immigrant & \\
\hline Household income & $\$ 100,000$ and greater & $\$ 24,999$ and under & $\$ 25,000-\$ 99,999$ \\
\hline
\end{tabular}


Table 3. Distribution of shifters in the Canadian sample $(\mathrm{N}=486)$

\begin{tabular}{lcccc}
\hline Shift & Proportion & Std. Err. & \multicolumn{2}{c}{$90 \%$ Conf. Interval } \\
\hline Risk averse (Tech A) & 0.64 & 0.022 & 0.604 & 0.676 \\
Turtling (Tech B $\rightarrow$ Tech A) & 0.06 & 0.010 & 0.038 & 0.073 \\
Traditional shift (Tech A $\rightarrow$ Tech B) & 0.20 & 0.018 & 0.166 & 0.225 \\
Risk seeking (Tech B) & 0.11 & 0.014 & 0.086 & 0.132 \\
\hline
\end{tabular}


Table 4. Summary of maximum likelihood estimates of $\beta$ and $\mu$, conditional on different sets of instruments

\begin{tabular}{cccccc}
\hline & Model 1 & Model 2 & Model 3 & Model 4 & Model 5 \\
& $(\mathrm{N}=459)$ & $(\mathrm{N}=329)$ & $(\mathrm{N}=360)$ & $(\mathrm{N}=431)$ & $(\mathrm{N}=380)$ \\
\hline$\beta$ & 0.4 & $1.3+$ & $2.0 * *$ & 0.9 & $3.5 * * *$ \\
$\mu$ & $-1.7 * * *$ & $-1.6 * * *$ & $-1.7 * * *$ & $-1.7 * * *$ & $-1.2 * * *$ \\
Order & 0.1 & -0.1 & 0.1 & 0.1 & 0.1 \\
\hline Instruments & & 28 & 22 & 19 & 9 \\
AIC & 207.4 & 56.0 & 64.8 & 87.9 & 140.2 \\
\hline
\end{tabular}

Note: Complete table of estimates and standard errors for each of the IV models is provides in Table A2 in the Appendix. $+p<.1 ; * p<.05 ; * * p<.01 ; * * * p<.001$ (two-tailed tests). 
Table A1. Turtling by socio-demographic attributes and their dominance (+/-) in the Canadian sample $(\mathrm{N}=486)$

\begin{tabular}{|c|c|c|c|c|c|}
\hline $\begin{array}{l}\text { Socio-demographic attribute } \\
\text { Gender }\end{array}$ & $\mathrm{N}$ & Proportion & Std. Err. & \multicolumn{2}{|c|}{$90 \%$ Conf. Interva } \\
\hline Male $(+)$ & 244 & 0.04 & 0.012 & 0.021 & 0.063 \\
\hline Female (-) & 239 & 0.07 & 0.017 & 0.048 & 0.104 \\
\hline \multicolumn{6}{|l|}{ Age } \\
\hline Millennial (-) & 94 & 0.09 & 0.029 & 0.048 & 0.146 \\
\hline Gen $\mathrm{X}$ & 196 & 0.06 & 0.016 & 0.034 & 0.090 \\
\hline Baby Boomer $(+)$ & 196 & 0.04 & 0.014 & 0.023 & 0.072 \\
\hline \multicolumn{6}{|l|}{ Family composition } \\
\hline Single & 107 & 0.05 & 0.02 & 0.02 & 0.09 \\
\hline Couple $(+)$ & 214 & 0.03 & 0.01 & 0.02 & 0.06 \\
\hline Couple with kids & 108 & 0.07 & 0.03 & 0.04 & 0.13 \\
\hline Single with kids (-) & 31 & 0.06 & 0.04 & 0.02 & 0.19 \\
\hline \multicolumn{6}{|l|}{ Visible minority } \\
\hline Identified (-) & 40 & 0.23 & 0.07 & 0.13 & 0.35 \\
\hline Non-identified $(+)$ & 444 & 0.04 & 0.01 & 0.03 & 0.06 \\
\hline \multicolumn{6}{|l|}{ Aboriginal identity } \\
\hline Identified (-) & 18 & 0.11 & 0.08 & 0.03 & 0.31 \\
\hline Non-identified $(+)$ & 466 & 0.05 & 0.01 & 0.04 & 0.07 \\
\hline \multicolumn{6}{|l|}{ Disability } \\
\hline Living with (-) & 71 & 0.04 & 0.02 & 0.02 & 0.11 \\
\hline Not living with $(+)$ & 414 & 0.06 & 0.01 & 0.04 & 0.08 \\
\hline \multicolumn{6}{|l|}{ Place of birth } \\
\hline Canada $(+)$ & 425 & 0.05 & 0.01 & 0.04 & 0.07 \\
\hline Abroad (-) & 60 & 0.08 & 0.04 & 0.04 & 0.16 \\
\hline \multicolumn{6}{|l|}{ Region of Canada } \\
\hline West & 172 & 0.06 & 0.02 & 0.04 & 0.10 \\
\hline Central $(+)$ & 241 & 0.04 & 0.01 & 0.02 & 0.07 \\
\hline Eastern (-) & 70 & 0.09 & 0.03 & 0.04 & 0.16 \\
\hline North $(-)$ & 3 & 0.00 & & & \\
\hline \multicolumn{6}{|l|}{ Household income } \\
\hline Under 24,999 (-) & 33 & 0.12 & 0.06 & 0.05 & 0.25 \\
\hline $25,000-49,999(-)$ & 74 & 0.04 & 0.02 & 0.02 & 0.10 \\
\hline $50,000-74,999$ & 87 & 0.05 & 0.02 & 0.02 & 0.10 \\
\hline $75,000-99,999$ & 67 & 0.04 & 0.03 & 0.02 & 0.11 \\
\hline $100,000-124,999(+)$ & 81 & 0.09 & 0.03 & 0.05 & 0.15 \\
\hline $125,000-149,999(+)$ & & 0.00 & & & \\
\hline 150,000 and above $(+)$ & 75 & 0.08 & 0.03 & 0.04 & 0.15 \\
\hline \multicolumn{6}{|l|}{ Highest level of education } \\
\hline High school or less $(-)$ & 42 & 0.07 & 0.04 & 0.03 & 0.17 \\
\hline Some technical degree & 107 & 0.03 & 0.02 & 0.01 & 0.07 \\
\hline Some university $(+)$ & 210 & 0.07 & 0.02 & 0.05 & 0.11 \\
\hline Postgraduate $(+)$ & 106 & 0.03 & 0.01 & 0.01 & 0.07 \\
\hline
\end{tabular}


Table A1. (continued)

\begin{tabular}{lccccc}
\hline Socio-demographic attribute & $\mathrm{N}$ & Proportion & Std. Err. & \multicolumn{2}{l}{$90 \%$ Conf. Interval } \\
\hline Occupation & & & & & \\
Management $(+)$ & 48 & 0.08 & 0.04 & 0.04 & 0.18 \\
Bussiness \& finance (+) & 66 & 0.02 & 0.02 & 0.00 & 0.08 \\
Natural Sciences $(+)$ & 25 & 0.08 & 0.06 & 0.02 & 0.23 \\
Health & 46 & 0.11 & 0.05 & 0.05 & 0.21 \\
Other & 127 & 0.05 & 0.02 & 0.02 & 0.09 \\
Sales \& services (-) & 49 & 0.10 & 0.04 & 0.05 & 0.20 \\
Trades \& manufacturing (-) & 59 & 0.00 & & & \\
Employment status & & & & & \\
Employed (+) & 284 & 0.05 & 0.01 & 0.03 & 0.08 \\
Unemployed (-) & 71 & 0.06 & 0.03 & 0.02 & 0.12 \\
Retired (-) & 122 & 0.05 & 0.02 & 0.03 & 0.09 \\
Work setting & & & & & \\
Academia & 31 & 0.03 & 0.03 & 0.01 & 0.15 \\
Large firm & 73 & 0.05 & 0.03 & 0.02 & 0.12 \\
Small/med firms & 125 & 0.02 & 0.01 & 0.01 & 0.06 \\
Social sector & 101 & 0.06 & 0.02 & 0.03 & 0.11 \\
Public service & 100 & 0.08 & 0.03 & 0.05 & 0.14 \\
\hline
\end{tabular}


Table A2. IV probit models of turtling, conditional on different sets of instruments, estimated using maximum liklihood (standard errors in brackets)

\begin{tabular}{|c|c|c|c|c|}
\hline & $\begin{array}{l}\text { Model } 2 \\
(\mathrm{~N}=329)\end{array}$ & $\begin{array}{c}\text { Model } 3 \\
(\mathrm{~N}=360)\end{array}$ & $\begin{array}{c}\text { Model } 4 \\
(\mathrm{~N}=431)\end{array}$ & $\begin{array}{l}\text { Model } 5 \\
(\mathrm{~N}=380)\end{array}$ \\
\hline \multicolumn{5}{|l|}{ Turtling } \\
\hline$\beta$ & $\begin{array}{l}1.257+ \\
(0.753)\end{array}$ & $\begin{array}{l}1.960 * * \\
(0.736)\end{array}$ & $\begin{array}{r}0.931 \\
(1.159)\end{array}$ & $\begin{array}{l}3.453 * * * \\
(0.607)\end{array}$ \\
\hline$\mu$ & $\begin{array}{l}-1.647^{* * *} \\
(0.159)\end{array}$ & $\begin{array}{l}-1.654^{* * *} \\
(0.163)\end{array}$ & $\begin{array}{l}-1.708 * * * \\
(0.145)\end{array}$ & $\begin{array}{l}-1.249 * * * \\
(0.279)\end{array}$ \\
\hline Order & $\begin{array}{r}-0.059 \\
(0.231) \\
\end{array}$ & $\begin{array}{r}0.096 \\
(0.209) \\
\end{array}$ & $\begin{array}{r}0.081 \\
(0.202) \\
\end{array}$ & $\begin{array}{r}0.128 \\
(0.154) \\
\end{array}$ \\
\hline \multicolumn{5}{|l|}{ Low income } \\
\hline Female & $\begin{array}{l}-0.031 \\
(0.026)\end{array}$ & $\begin{array}{r}-0.005 \\
(0.024)\end{array}$ & $\begin{array}{r}-0.006 \\
(0.023)\end{array}$ & \\
\hline \multicolumn{5}{|l|}{ Age group (Gen X ommitted) } \\
\hline Millennial & $\begin{array}{r}0.040 \\
(0.032)\end{array}$ & $\begin{array}{l}0.062 * \\
(0.031)\end{array}$ & $\begin{array}{r}0.047 \\
(0.032)\end{array}$ & \\
\hline Baby Boomer & $\begin{array}{l}0.056+ \\
(0.032)\end{array}$ & $\begin{array}{l}0.043+ \\
(0.024)\end{array}$ & $\begin{array}{r}0.014 \\
(0.026)\end{array}$ & \\
\hline \multicolumn{5}{|l|}{$\begin{array}{l}\text { Family composition (single without } \\
\text { kids ommitted) }\end{array}$} \\
\hline Single & $\begin{array}{l}0.190 * * * \\
(0.029)\end{array}$ & $\begin{array}{l}0.172 * * * \\
(0.029)\end{array}$ & $\begin{array}{l}0.177^{* * *} \\
(0.029)\end{array}$ & \\
\hline Couple with kids & $\begin{array}{l}-0.007 \\
(0.029)\end{array}$ & $\begin{array}{r}-0.028 \\
(0.028)\end{array}$ & $\begin{array}{r}0.005 \\
(0.030)\end{array}$ & \\
\hline Single with kids & $\begin{array}{c}0.088 * \\
(0.044)\end{array}$ & $\begin{array}{l}0.084+ \\
(0.044)\end{array}$ & $\begin{array}{l}0.079+ \\
(0.046)\end{array}$ & \\
\hline Visible minority & $\begin{array}{r}0.056 \\
(0.046)\end{array}$ & $\begin{array}{r}0.055 \\
(0.045)\end{array}$ & $\begin{array}{r}0.068 \\
(0.050)\end{array}$ & \\
\hline Aboriginal identity & $\begin{array}{l}-0.018 \\
(0.059)\end{array}$ & $\begin{array}{r}0.015 \\
(0.056)\end{array}$ & $\begin{array}{r}-0.010 \\
(0.063)\end{array}$ & \\
\hline Living with disability & $\begin{array}{r}0.022 \\
(0.038)\end{array}$ & $\begin{array}{l}0.061+ \\
(0.034)\end{array}$ & $\begin{array}{l}0.127 \text { *** } \\
(0.035)\end{array}$ & \\
\hline Born abroad & $\begin{array}{l}-0.015 \\
(0.039)\end{array}$ & $\begin{array}{c}-0.008 \\
(0.036)\end{array}$ & $\begin{array}{c}-0.012 \\
(0.036)\end{array}$ & \\
\hline \multicolumn{5}{|l|}{$\begin{array}{l}\text { Region of Canada (Central } \\
\text { ommitted) }\end{array}$} \\
\hline West & $\begin{array}{r}0.060 * \\
(0.025)\end{array}$ & $\begin{array}{c}0.059 * \\
(0.023)\end{array}$ & $\begin{array}{r}0.029 \\
(0.025)\end{array}$ & \\
\hline Eastern & $\begin{array}{l}0.064+ \\
(0.033)\end{array}$ & $\begin{array}{l}0.054+ \\
(0.032)\end{array}$ & $\begin{array}{r}-0.004 \\
(0.034)\end{array}$ & \\
\hline North & $\begin{array}{l}-0.069 \\
(0.200)\end{array}$ & $\begin{array}{r}0.033 \\
(0.144)\end{array}$ & $\begin{array}{r}0.028 \\
(0.165)\end{array}$ & \\
\hline \multicolumn{5}{|l|}{$\begin{array}{l}\text { Highest level of education (at least } \\
\text { some university ommitted) }\end{array}$} \\
\hline High School or less & $\begin{array}{c}0.098 * \\
(0.041)\end{array}$ & $\begin{array}{r}0.090 * \\
(0.039)\end{array}$ & & $\begin{array}{c}0.088 * \\
(0.045)\end{array}$ \\
\hline Some technical degree & $\begin{array}{l}-0.026 \\
(0.030)\end{array}$ & $\begin{array}{r}-0.004 \\
(0.029)\end{array}$ & & $\begin{array}{r}-0.024 \\
(0.027)\end{array}$ \\
\hline
\end{tabular}


Table A2. (continued)

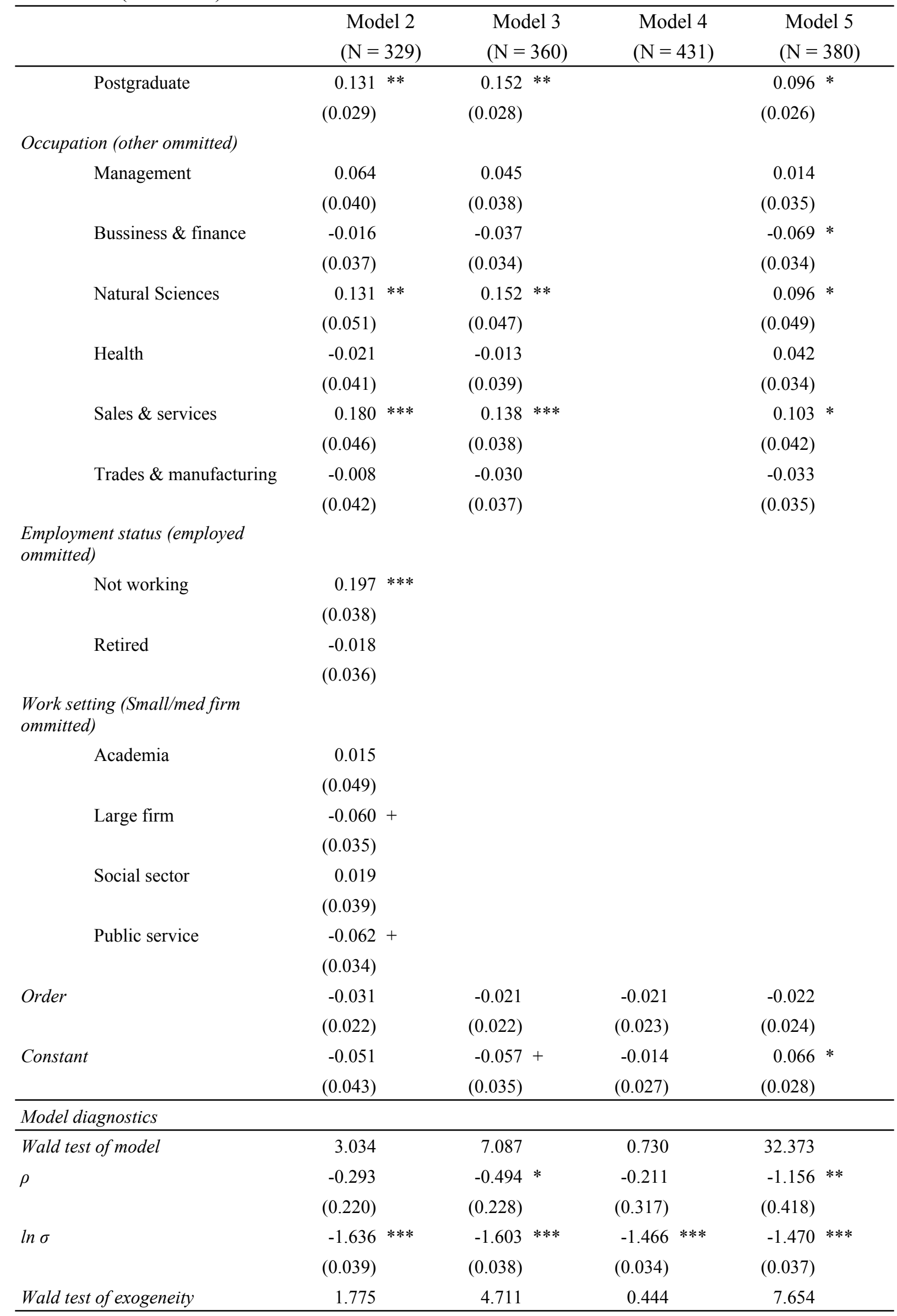

$+\mathrm{p}<.1{ }^{*} \mathrm{p}<.05 ; * * \mathrm{p}<.01 ; * * * \mathrm{p}<.001$ (two-tailed tests). 